\title{
OPPORTUNITIES AND CHALLENGES IN THE IMPLEMENTATION OF BUILDING INFORMATION MODELLING FOR PREFABRICATION OF HEATING, VENTILATION AND AIR CONDITIONING SYSTEMS IN SMALL AND MEDIUM-SIZED CONTRACTING COMPANIES IN GERMANY: A CASE STUDY
}

\author{
NIJANTHAN MOHAN, ROLF GROSS, KARSTEN MENZEL \& FABIAN THEIS \\ Aachen University of Applied Sciences, Dresden University of Technology
}

\begin{abstract}
Even though BIM (Building Information Modelling) is successfully implemented in most of the world, it is still in the early stages in Germany, since the stakeholders are sceptical of its reliability and efficiency. The purpose of this paper is to analyse the opportunities and obstacles to implementing BIM for prefabrication. Among all other advantages of BIM, prefabrication is chosen for this paper because it plays a vital role in creating an impact on the time and cost factors of a construction project. The project stakeholders and participants can explicitly observe the positive impact of prefabrication, which enables the breakthrough of the scepticism factor among the small-scale construction companies. The analysis consists of the development of a process workflow for implementing prefabrication in building construction followed by a practical approach, which was executed with two case studies. It was planned in such a way that, the first case study gives a first-hand experience for the workers at the site on the BIM model so that they can make much use of the created BIM model, which is a better representation compared to the traditional $2 \mathrm{D}$ plan. The main aim of the first case study is to create a belief in the implementation of BIM Models, which was succeeded by the execution of offshore prefabrication in the second case study. Based on the case studies, the time analysis was made and it is inferred that the implementation of BIM for prefabrication can reduce construction time, ensures minimal wastes, better accuracy, less problem-solving at the construction site. It was observed that this process requires more planning time, better communication between different disciplines, which was the major obstacle for successful implementation. This paper was carried out from the perspective of small and medium-sized mechanical contracting companies for the private building sector in Germany. Keywords: building information modelling, HVAC, prefabrication, construction, small and medium scaled companies.
\end{abstract}

\section{INTRODUCTION}

The construction industry is witnessing a paradigm shift that tends to achieve higher productivity, efficiency, quality, sustainability and infrastructure value while reducing the life cycle costs and time of a project [1]. The evolution of computers and information technology lead to a digital revolution in the AEC industry, which in turn gave rise to the BIM technique. BIM is a process that generates and manages digital representations of buildings, in terms of both physical and functional characteristics [2]. Over the past 20 years, the BIM technique has been successfully adopted in different parts of the world and has been beneficial for all the stakeholders involved in a project. On December 15, 2015, the Federal Ministry of Transport and Digital Infrastructure (FMTI) in cooperation with Planen-Bauen 4.0 $\mathrm{GmbH}$ proposed a three-step plan (Fig. 1) for implementation of BIM for road and rail projects over the period from 2015-2020 [3]. Even though Germany is in the pilot phase of the implementation process, many companies are still hesitant about exploring the capabilities of BIM. 


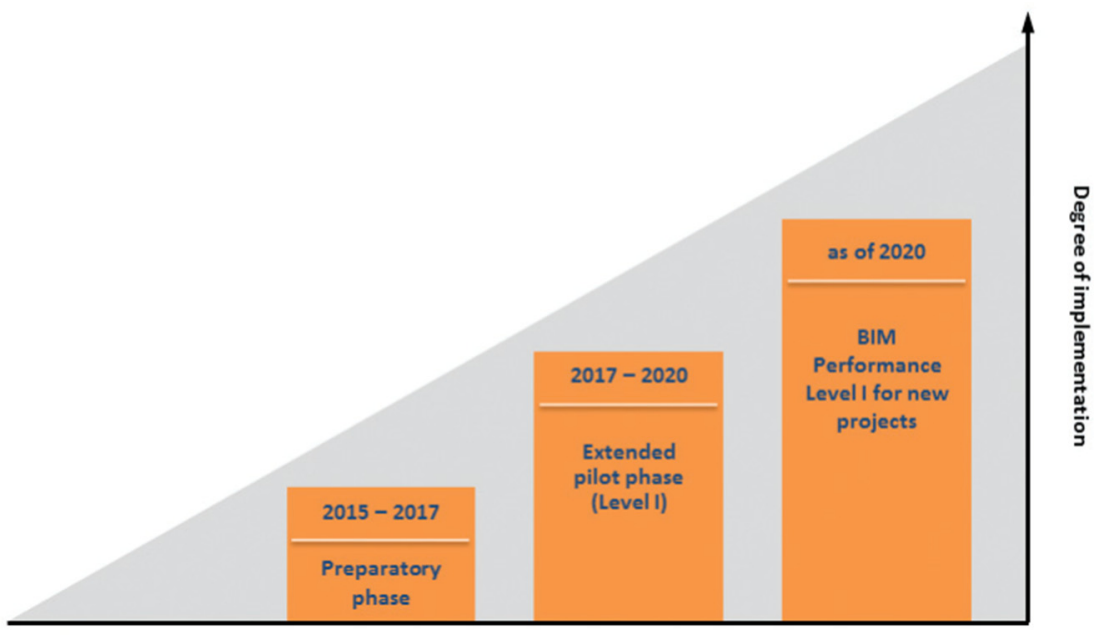

Figure 1: Phases in the implementation of BIM in Germany [6].

The most common misconception among the stakeholders is limiting BIM to 3D modelling software. BIM is not only a software but a holistic process that integrates process, people and the software platform establishing a well-coordinated workflow among parties involved in a project. Another common misconception about BIM is the assumption that this concept is suitable only for larger firms and projects that are more significant. The BIM concept is equally beneficial irrespective of the size of the project or the company, as in either case the financial costs occurred is the same, albeit on different scales [4].

\section{PROBLEM STATEMENT}

The major problem in the HVAC construction industry is the ineffective communication and coordination between different disciplines involved in a project which results due to the stocking of information among the stakeholders. Therefore, most of the decisions are made on the construction site under the pressure of project deadlines which results in a lot of rework and manual creation of additional documents.

The traditional two-dimensional (2D) plans are individual plans that do not have digital coordination (information about pumps, valves etc.) with the drawings of the other disciplines. Therefore, a change made in one of the plans should be incorporated in others manually thereby increasing the chances of errors occurring in the documentation. 2D plans have a limited understanding among the installers at the construction site, which marks the necessity for a better representation of the models. The consequence of a manually developed bill of materials results in an incorrect order for components thereby delaying the project delivery.

The current trends in the potential and status of implementation of digitalisation processes of the construction companies in Germany are illustrated in Fig. 2. From the statistics, it is evident that the contracting companies have a huge potential to use various technologies for digitalisation in construction but the implementing methods are still lacking. This is mainly due to the high risks concerning the huge investments (human resource, software and hardware) and demanding effective communication and coordination process with BIM. The above-stated reasons result in reluctance with the small and medium scale contracting companies in adapting to digitalisation/BIM process for construction. 


\section{Potentials and Capabilities of Contracting Companies in Germany}

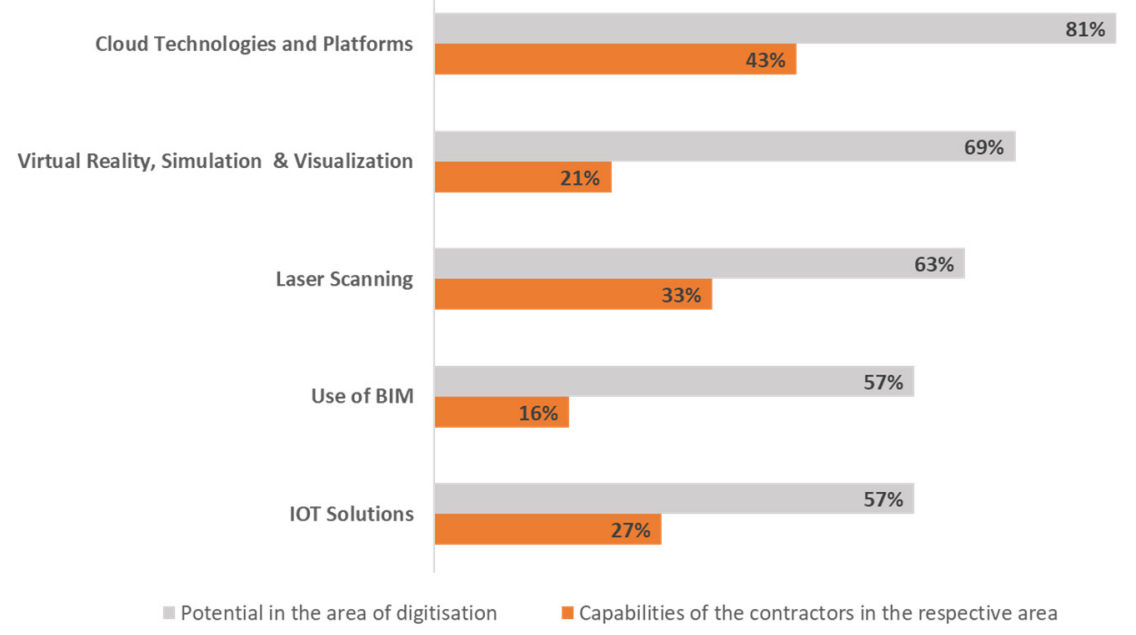

Figure 2: Potential and skills of digitalisation of construction companies in Germany. (Source: Digitalisierung der Bauindustrie, PwC-Studie, December 2020.)

The BIM workflow is not a concrete guideline but rather tailor-made for an organisation according to its capabilities and requirements. At the world stage, the BIM concept was proposed as a solution to enhance communication and coordination in a construction project. It guides an organisation to develop a standardised workflow to enrich the process and procedures administered at the firm. BIM emphasises Virtual Design and Construction (VDC), i.e., a 3D model as a digital twin of the project is developed which enables the user to resolve any discrepancies before going into construction. The 3D model also provides better representation for the installers and facilitates the prefabrication of the components. Model-based material lists ensure optimal ordering of materials and reduce wastage at the construction site. Overall, the implementation of a BIM workflow aids an organisation to produce detailed, high-quality plans and documentation for a project, while also optimising the time taken for construction.

In this context, the prefabrication process (an advantage of BIM) was selected for the study to depict the opportunities and challenges as it is a more hands-on process and has a direct impact on the workflow at the construction site.

\section{BIM FOR PREFABRICATION}

Without BIM, designing prefabricated Mechanical Electrical and Plumbing (MEP) system components becomes an uphill struggle, and contractors risk creating parts and pieces that may not be compatible with each other as planned once installed on the construction site.

However, using highly detailed and coordinated BIM 3D models of various architectural and MEP systems, each trade contractor can be confident that their system will fit and be installed according to the planned design. According to the above-mentioned, the following process flow for the design and construction of HVAC systems with the prefabrication process was developed. 
Fig. 3(a) depicts the design process of a construction company (contractors) in Germany. The execution drawings or 3D model are received from the engineering planning office and the manufacturer-specific information (geometry and technical specification) of the components are added and thereby the installation drawings are developed by the contracting companies. A coordination and collision check is to be carried out with other trades to avoid discrepancies during construction. Using the coordinated model, assembly/fabrication part drawings are developed which is to be followed by the execution of material procurement and fabrication process.

The installation process of a construction company (contractors) in Germany is depicted in Fig. 3(b). The procurement/fabrication process is followed by the transportation and logistics of the components at the construction site. The components are then installed at the planned positions and an inspection is carried out. Once all the parameters are checked, the system is commissioned and simultaneously the as-built documentation is prepared.

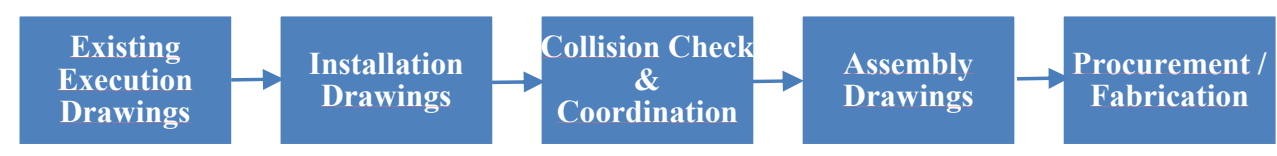

(a)

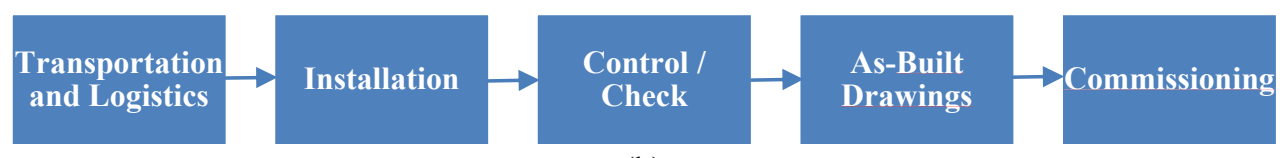

Figure 3: Proposed process flow diagram for a mechanical contracting company with prefabrication method (a) Design process; and (b) Installation process.

The case study on the opportunities and obstacles of implementing prefabrication process for the construction of HVAC system (mechanical rooms) was carried out in two phases.

\subsection{Case study 1: On-site fabrication process with BIM models}

The case study aimed to introduce and integrate the use of BIM models at construction sites as an advancement from traditional 2D drawings. Instead of the conventional installation at the respective rooms, a fabrication tent was constructed at the site and the welders fabricated the installation parts using drawings from the BIM model. This provided an opportunity for the installers to cross check with the actual installation position and get adapted to the use of 3D models at construction sites. Fig. 4 depicts the execution of case study 1 at a construction site.

Fig. 4(a) illustrates the BIM model of an HVAC technical room (with two buffer tanks and heat exchangers for space heating \& cooling purposes), which was developed with a level of detail 500 using Autodesk Revit Software. The components used in the model, such as valves, buffer storage and pumps, were obtained directly from the manufacturer and are the digital replica of the procured components for the project. The HVAC BIM Model was coordinated with other disciplines like electrical and plumbing, and the final collision-free drawings and model was provided to the installers at the construction site. 

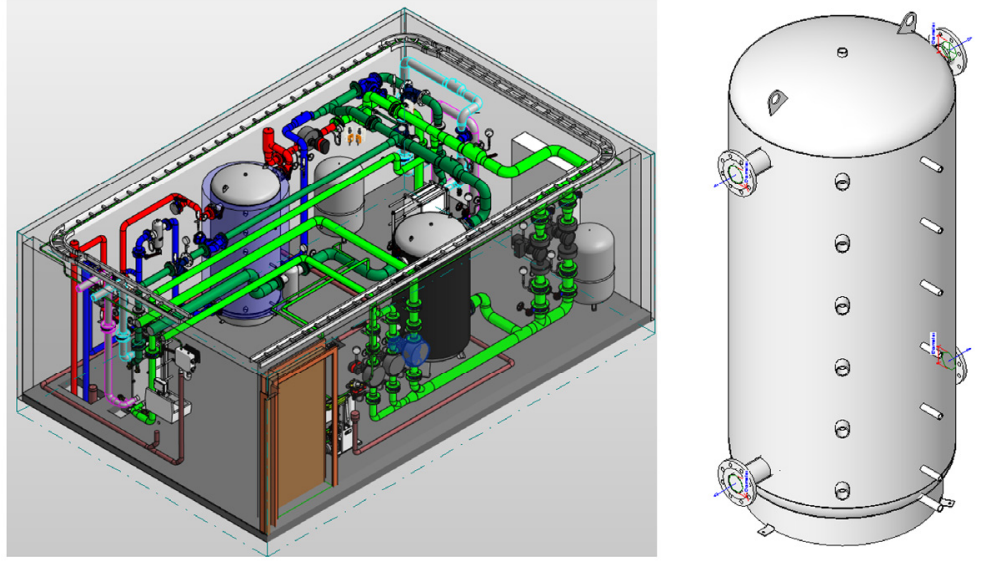

(a)
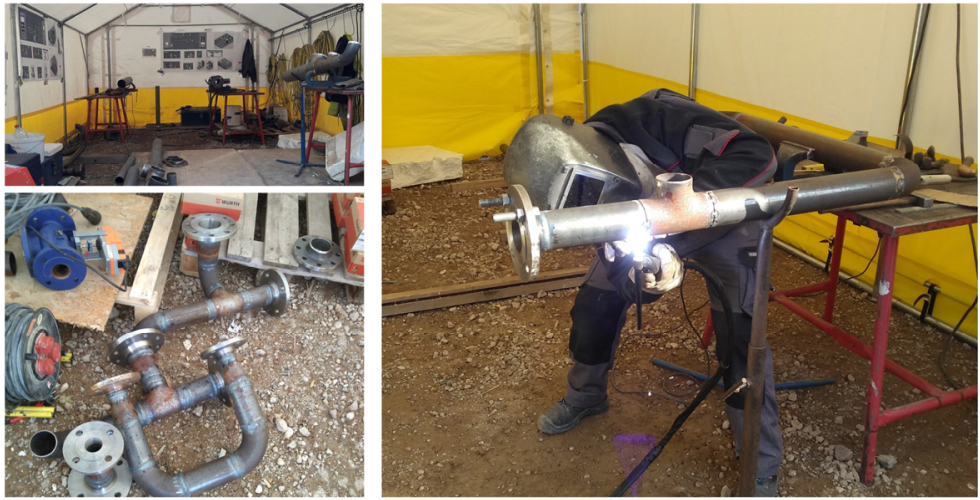

(b)
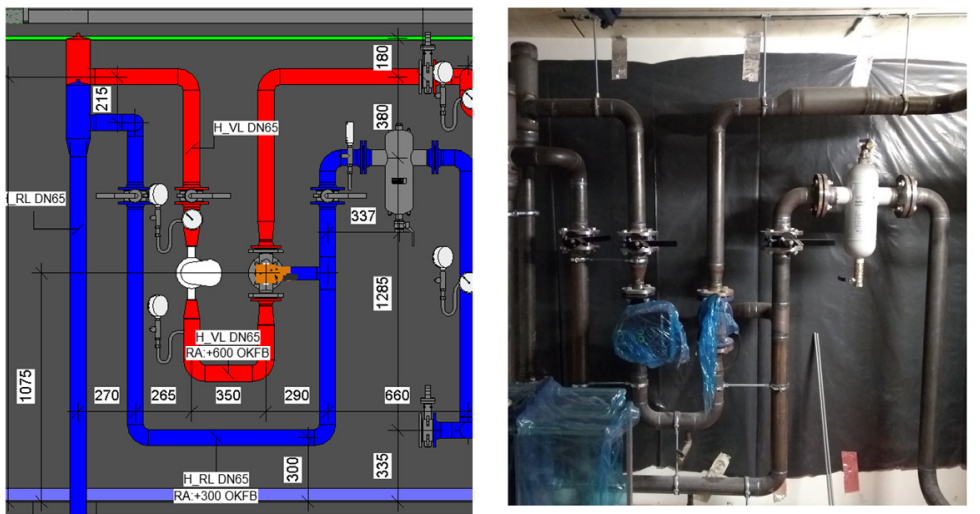

(c)

Figure 4: Execution of case study 1 - On-site prefabrication. (a) BIM model with manufacturer-specific components; (b) Fabrication tent; and (c) Comparison between BIM model and as-built. 
The fabrication tent is depicted in Fig. 4(b). Based on the collision-free drawings, the assembly parts were fabricated outside of the technical room. The pieces were assembled at the planned positions in the technical room, and a comparison photo of the BIM model to that of the as-built condition is shown in Fig. 4(c).

\subsection{Case study 2: On-site fabrication process with BIM model}

The case study aimed to examine the changes and challenges in implementing the prefabrication process with BIM models using external service providers. In this method, the model of the technical room was split into different assembly part drawings (Fig. 5(a)) and was made available to an external service provider who delivers the finished fitting pieces of the HVAC systems. As mentioned in Fig. 3(a), to avoid onsite difficulties during the installation process, the individual trade model was thoroughly coordinated with other trades and was approved by the general contractor before the draft of the assembly drawings. Each dimension, such as pipe diameters, length and pressure rating of the flanges, were depicted extensively in the assembly drawings to avoid discrepancies during fabrication and installation.

Fig. 5(b) depicts the delivery of fabricated parts to the warehouse and the sorting process of the individual components before transportation to the construction site.

The pipe fitting pieces were then transported to the construction site, similar to HVAC machines like chillers, boilers, etc. The parts were marked with an identification system for easy sorting at the project site. The final assembly of the pipe fitting pieces is illustrated in Fig. 5(c).

\section{RESULT ANALYSIS}

Using the above-mentioned case studies, a comparison between the conventional construction process to that of the process with prefabrication using BIM models have been made for time parameter and are illustrated in the graphs shown in Fig. 6.

The first column depicts the time taken for the design of the technical room. It involves modelling and coordination with other disciplines. The time taken for on-site planning (Fig. 6(a))/for prefabrication (Fig. 6(b)) and installation at the project site has been illustrated in the second column. The percentage of time consumed for recording the as-built condition is shown in the third column.

From the graphs, it is inferred that the percentage of time taken for design is higher in the prefabrication process because of the more work required for creating assembly drawings and for coordination. The higher design time, in turn, is compensated by the reduction in onsite planning and installation as the BIM model is a digital twin of the technical room, which was extensively coordinated. As the BIM model is a replica of the real-time project site, the time taken for recording the as-built condition is considerably lesser than that of the conventional process.

The above graphs illustrate that the process using prefabrication with BIM models takes about twice the amount of time in the design phase that includes the creation of construction drawings, coordination and collision checks in comparison with the traditional method. The time taken for installation and creation of as-built documents in the prefabrication process is less in comparison with the conventional process. The values of the graphs have been collected with various interactions with the installers at the project site. 

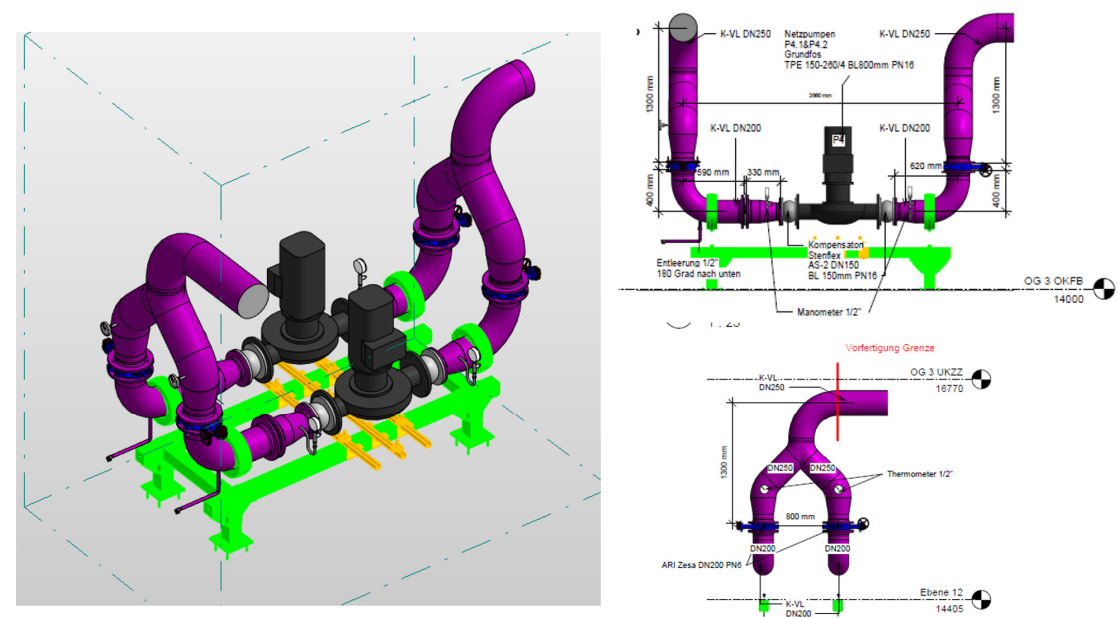

(a)
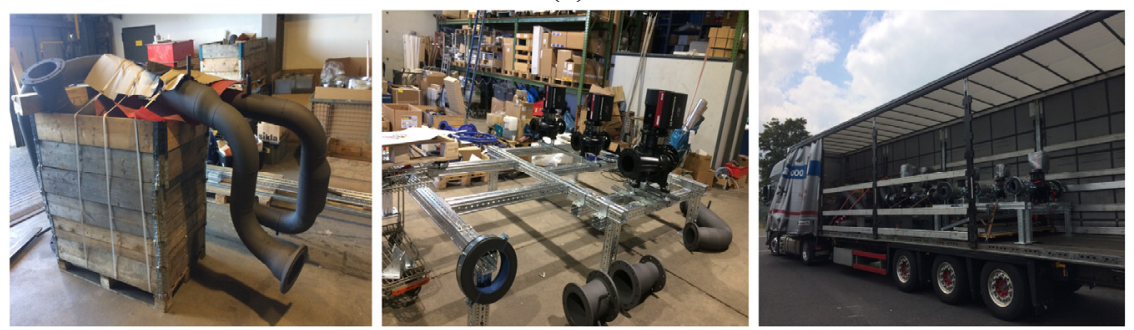

(b)

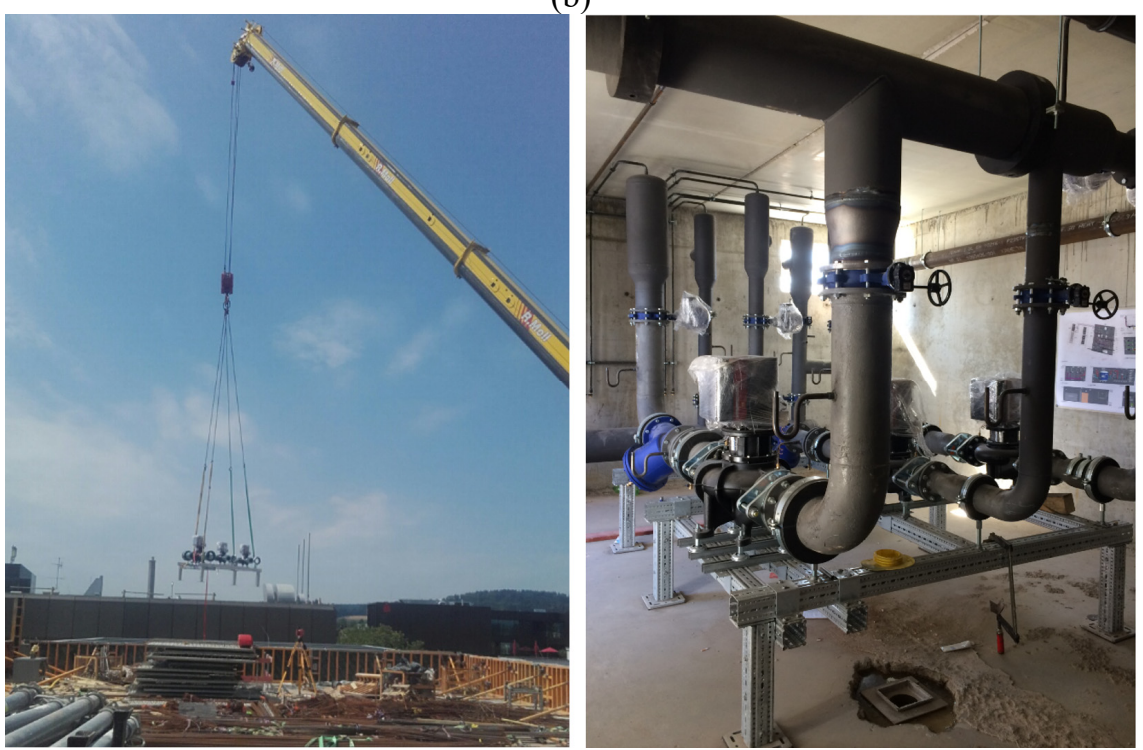

(c)

Figure 5: Execution of case study 2-Offshore prefabrication. (a) Assembly drawing with manufacturer-specific components; (b) Prefabricated fitting pieces; and (c) Transportation and installation. 


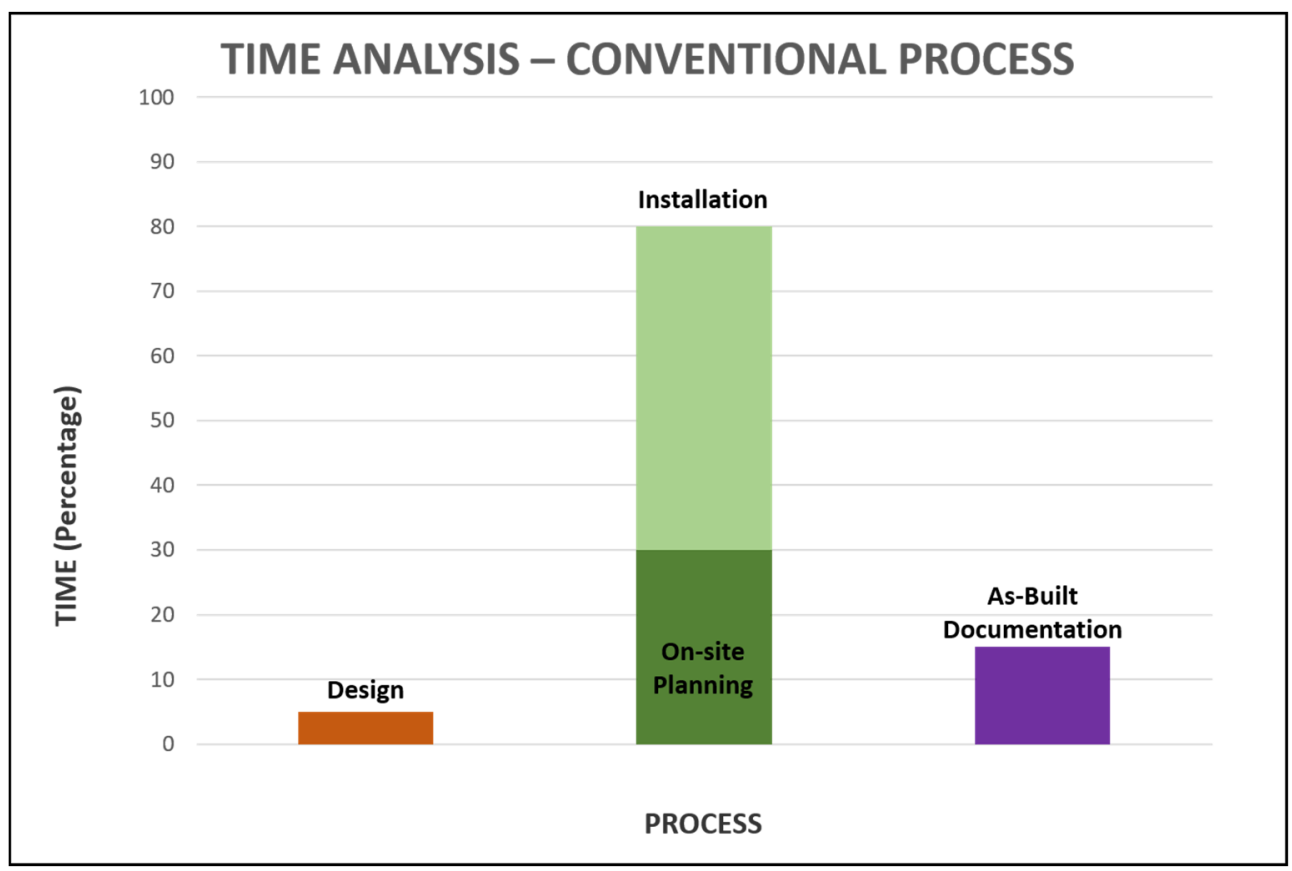

(a)

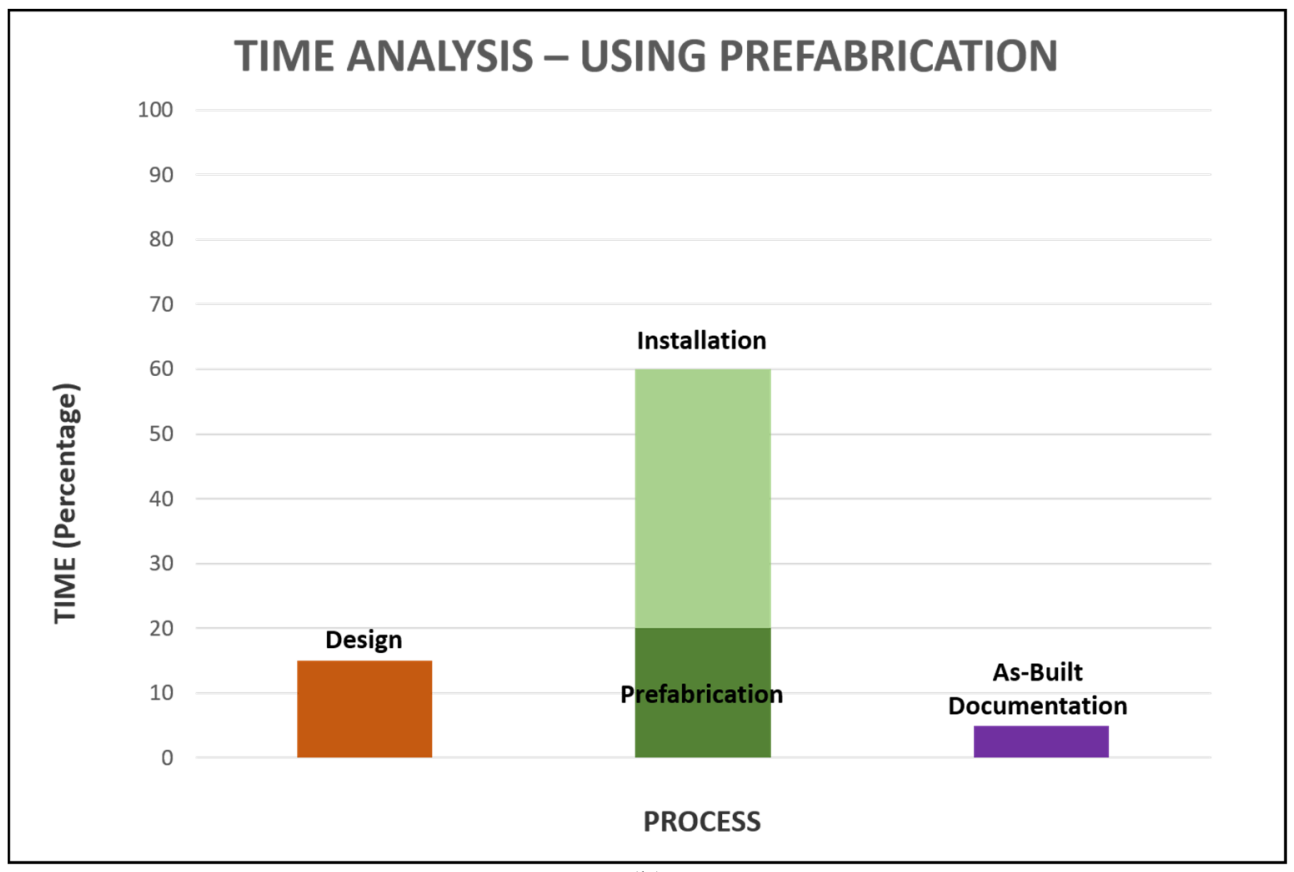

(b)

Figure 6: Time analysis. (a) Conventional process; and (b) Using prefabrication process with BIM models. 


\subsection{SWOT analysis}

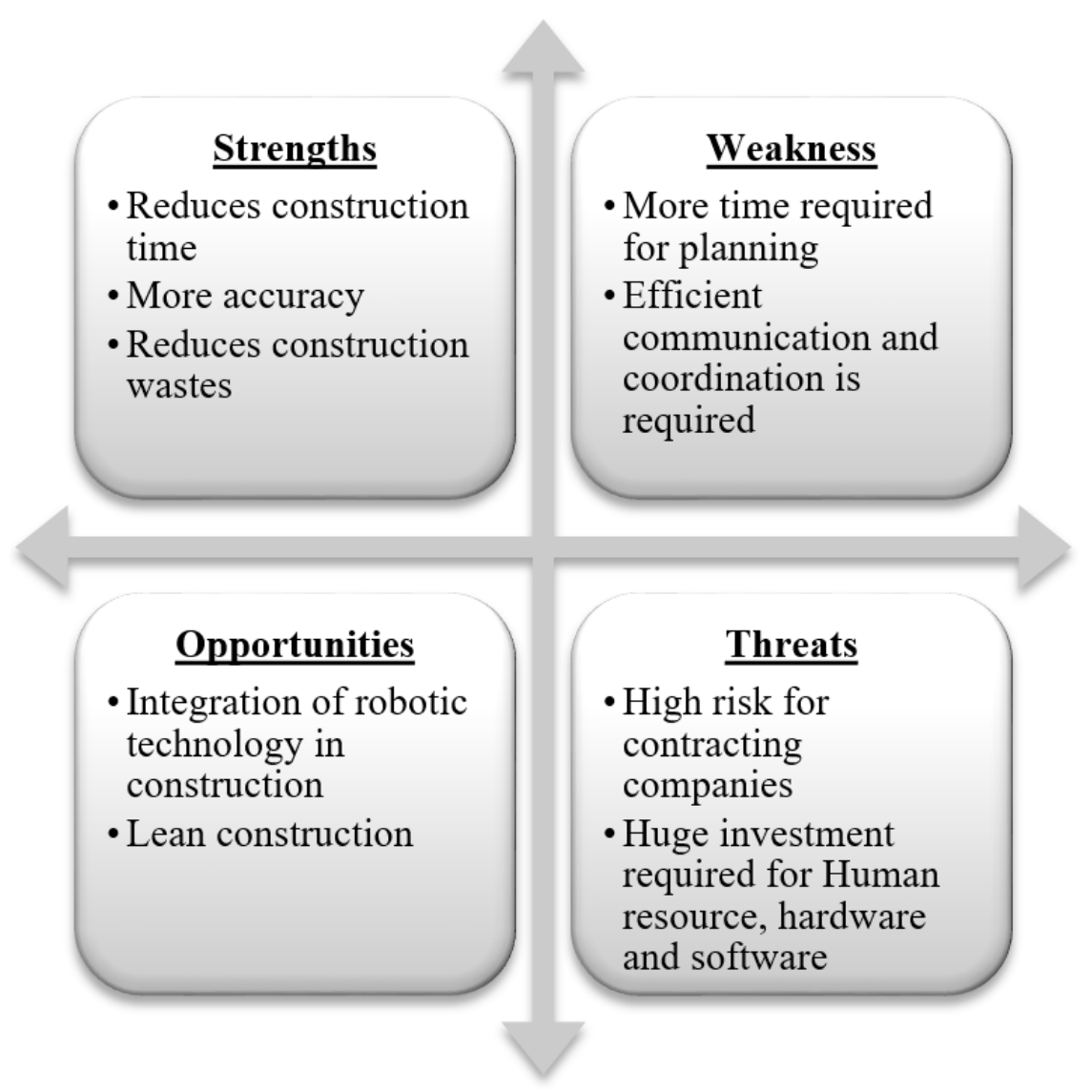

Figure 7: SWOT matrix - BIM for prefabrication of HVAC systems.

\section{CONCLUSION}

BIM is neither just technology nor just software. BIM is a best-practice process for the AEC industry, and like any other concepts such as PRojects IN Control Environments (PRINCE2), Agile development etc., BIM has its impact on project management, project coordination and procurement processes in an organisation.

Even though the prefabrication process requires more time in the design phase, it reduces the time taken for installation and creation of as-built documents that in turn results in an overall reduction of about $20 \%$ of the time taken for the construction process. The reduction in the time consumption reflects directly with the costs incurred. The contracting company can reduce their costs up to $15 \%$ (considering the loss in the profit margin for the materials such as pipes and pipe fittings - which are supplied by the external service providers), thereby benefitting the contractors.

Implementation of BIM for prefabrication of HVAC systems may seem an ambitious endeavour because of its diverse components, extensive information data and high capital. 
However, when done right, it will open a new frontier for the profile and capabilities of an organisation.

\section{ACKNOWLEDGEMENTS}

We would like to express our sincere thanks to the management and the employees of Wilhelm Theis $\mathrm{GmbH}$, a mechanical contracting company in Germany for supporting us in the implementation of the research work. Furthermore, we would like to thank the research groups at the Institute of Building Informatics, Dresden University of Technology and the Department of Civil Engineering - Smart Building Engineering, Aachen University of Applied Sciences for their valuable inputs on this research work.

\section{REFERENCES}

[1] Wadhah, A.H., Abbas, M.A. \& Nagham, N.A., Motivation factors for adopting building information modeling (BIM) in Iraq. Engineering, Technology \& Applied Science Research, p. 1, 2018.

[2] How Building Information Modeling (BIM) Has Revolutionized the Construction Industry. $\quad \mathrm{https} / /$ www.viatechnik.com/blog/building-information-modeling-bimrevolutionized-construction-industry/. Accessed on: 31 May 2021.

[3] Bastian, F., BIM - Status of implementation in Germany. Annual Conference of the European Society of Law, University of Fribourg, Switzerland, pp. 4-9, 2017.

[4] David, P., Paul, S. \& Stefan, M., Building Information Modelling for Dummies, John Wiley, pp. 345-350, 2016.

[5] Valluru, P., Karlapudi, J., Menzel, K., Mätäsniemi, T. \& Shemeika, J., A semantic data model to represent building material data in AEC collaborative workflows. Boosting Collaborative Networks 4.0. PRO-VE 2020. IFIP Advances in Information and Communication Technology. Springer, vol. 598, 2020.

[6] Stufenplan Digitales Planen und Bauen, Bundesministerium für Verkehr und digitale Infrastruktur, Germany, p. 5. https://www.bmvi.de/SharedDocs/DE/Publikationen/DG/ stufenplan-digitales-bauen.pdf?_blob=publicationFile. Accessed on: 30 May 2021.

[7] https://theis-gmbh.de/. Accessed on: 30 May 2021. 